\title{
Postsyntactic inflection of the degree phrase in German
}

\author{
Emily A. Hanink*
}

\begin{abstract}
Recent treatments of concord contend that adjectival inflection occurs postsyntactically through the insertion of Agr nodes onto individual, concord-bearing heads after Spell-Out (i.a. Norris 2012, 2014). I examine these claims through the lens of degree modification in German, which demonstrates that current formulations of this approach are untenable. I argue however that a postsyntactic treatment of (adjectival) concord can in fact be maintained if Agr node insertion occurs phrasally at DegP, and not at adjectival heads. This account explains i) an observed difference between the inflection of analytic vs. synthetic degree expressions in both simple and complex modifiers, and ii) a puzzle involving across-the-board inflection of coordinated adjectives, which I argue to involve pointwise attachment of Agr.
\end{abstract}

Keywords. concord; German; inflection; degree phrases; degree modification

1. Introduction. Recent accounts of concord advance the view that inflection in the nominal domain is re-alized in the postsyntactic component of the grammar (building on i.a. Halle and Marantz 1993; Bobaljik 2008). In particular, Norris (2012, 2014) contends that DP-internal agreement is real-ized by the insertion of Agr nodes - a type of dissociated mopheme (Noyer 1997) - onto individ-ual, concord-bearing heads after Spell-Out (see also i.a. Baier 2015; Sigurðsson 2015; Deal 2016; Pietraszko 2017). A consequence of this proposal is that inflection is realized on heads only, and that if a head can realize inflection, it necessarily does so.

I examine this approach against data from German, which are problematic for an account along these lines. To preview the problem, consider the examples in (1), in which the noun Auto ('car') is preceded by the complex modifier brauner als braunes ('browner than brown'):

a. ein [braun-er als braun-es] Auto

a brown-COMP than brown-INFL car

b. *ein [braun-er-es als braun(-es)] Auto

a brown-COMP-INFL than brown-INFL car

'a car that's browner than brown.'

(Roehrs 2006: 222)

In complex modifiers of this kind, only the right-most adjective - in this case braun ('brown') - may be inflected (i.a. van Riemsdijk 1998; Grosu 2003; Roehrs 2006). Notably, the inflected adjective is not the head of the modifier: the comparative adjective (brauner) 'browner' remains bare. Crucially, the pattern of phrasal inflection as in (1) cannot be captured by accounts along the lines of Norris (2014), in which Agr node insertion is defined at the level of the head only: such an account cannot explain why only the rightmost, non-head adjective is inflected.

In this paper, I put forward a modified proposal for postsyntactic inflection that can account for the German inflectional pattern shown in (1), as well as other patterns of inflection in the language that are incompatible with Norris's postsyntactic approach to concord. While I build on

\footnotetext{
* Many thanks are due to Artemis Alexiadou, Karlos Arregi, and Jason Merchant for their invaluable feedback on this project, as well as to the RUESHeL research group at the Humboldt-Universität zu Berlin and the audience at LSA 92. For German judgments I thank Nils Hirsch, Doro Hoffmann, Jens Hopperdietzel, Florian Schäfer, and Livia Sommer. Author: Emily A. Hanink, University of Chicago (eahanink@uchicago.edu).
} 
proposals along the lines of Norris $(2012,2014)$, I argue instead that Agr node insertion occurs at the phrasal level - in particular, at DegP - rather than at the level of the head.

The structure of this paper is as follows. In $\S 2$, I present data from synthetic and analytic degree expressions, laying out the current problem for Norris's account in more detail. In $\$ 3$, I present the proposal and then provide support with further data from complex degree modifiers such as that in (1) in $\S 4$. In $\S 5$, I turn to an apparent case of non-phrasal inflection in German coordinate stuctures, showing how the proposal extends to such cases if we assume that Agrmorphemes may undergo pointwise attachment. Finally, $\$ 6$ concludes.

2. Synthetic vs. analytic degree expressions. Norris's (2014) treatment of concord proposes that, while agreement occurs in the syntax, the realization of inflection is always determined postsyntactically. His proposal can be character-ized by three key aspects: i) the postsyntactic realization of inflection is determined on a head-by-head basis; ii) only these heads, call them concord-bearing elements, trigger Agr node insertion; and iii) it is only where Agr is inserted that inflection may be realized. The formulation of Nor-ris's rule for Agr node insertion is given in (2), where $\mathrm{X}$ is determined language-specifically.

(2) Agr node insertion: $\mathrm{X}^{0} \rightarrow\left[\mathrm{X}^{0} \mathrm{Agr}^{0}\right]_{X}$

Norris (2014: 151)

Data from German show that (2) cannot be right, at least for adjectival inflection. ${ }^{1}$ This is because in the general case, adjectives are concord-bearing elements that agree with $\mathrm{N}$ in case, gender, and number when in attributive position (predicative adjectives do not agree). Henceforth, particular sets of $\phi$-features will be glossed simply as INFL:
a. die klug-e Frau
the clever-INFL woman
'the clever women'
b. ein schnell-es Auto
a fast-INFL car
'a fast car'
c. den gro $\beta$-en Männern
the tall-INFL men
'the tall men'

\author{
neuter accusative singular \\ feminine nominative singular \\ masculine dative plural
}

Despite this pattern however, in the case of attributive comparatives (4) and superlatives (5), inflection must surface outside the degree morpheme, and is not adjacent to the adjective:

(4) comparative -er
a. ein schnell-er-es Auto
a fast-COMP-INFL car
'a faster car'
b. *ein schnell-es-er Auto
a fast-INFL-COMP car
Intended: 'a faster car'

\footnotetext{
${ }^{1}$ Norris also accounts for other inflection-bearing heads, i.a. Num, which I do not address here.
} 
a. das schnell-st-e Auto

the fast-SPRL-INFL car

'the fastest car'

b. *das schnell-e-st Auto

the fast-INFL-SPRL car

Intended: 'the fastest car'

If adjectives are concord-bearing elements in the language, they should always trigger Agr node insertion according to Norris's proposal; we would therefore expect (4b) and (5b) to be grammatical. One possible explanation for the observed pattern, which we can immediately reject, is simply that Deg is a concord-bearing head in German, licensing inflection. This is not the case: in analytic degree expressions, the degree head (e.g. so, below) may never host inflection:

(6) ein so(*-es) schlecht-es Hotel

a SO-INFL bad-INFL hotel

'so/as bad a hotel'

Wood \& Vikner (2011: 94)

The generalization that emerges from this set of data is that Deg bears inflection just in case it is suffixed onto A. Given Norris's account, these facts are only compatible if we adopt a lexicalist approach according to which synthetic degree expressions are formed pre-syntactially in the lexicon (Kiparsky 2005); this approach would predict that inflection occurs outside Deg in the case of synthetic degree forms. However, given recent lines of inquiry showing that analytic and synthetic forms are in competition (Bobaljik 2012), it is desirable to maintain the assumption that degree expressions are not pre-formed in the lexicon, but are derived in the syntax.

3. Proposal. The proposal that I put forward to address these concerns is that Agr nodes are inserted postsyntactically at DegP, rather than at terminal nodes. Below, I adopt the proposal that AP is housed in DegP (Abney 1987; Corver 1990, 1997; Grimshaw 1991; Kennedy 1999). The struc-ture of a comparative is then as in (7), after the head of AP head-moves to Deg in the syntax: $:^{2}$

a. ein schnell-er-es Auto

a fast-COMP-INFL car

'a faster car'

b.

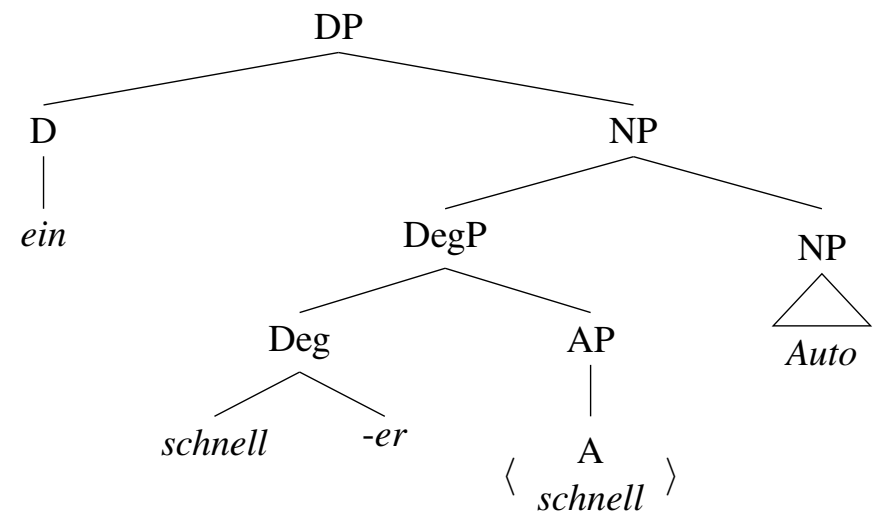

${ }^{2}$ I omit the implicit degree variable that takes the place of an overt standard of comparison, cf. Alrenga et al. (2012). 
Now, given this structure, Norris's formulation of Agr node insertion erroneously predicts the following unattested inflectional pattern, as Agr will be inserted at A and not Deg:

(8) *ein schnell-es-er Auto

a fast-INFL-COMP car

Intended: 'a faster car'

To remedy this problem, I propose an alternate rule according to which Agr is inserted at DegP:

(9) Agr node insertion (for adjectival concord): $\mathrm{DegP} \rightarrow\left[\mathrm{DegP} \mathrm{Agr}^{0}\right]_{\operatorname{Deg} P} / \ldots \mathrm{NP}$

Another way to think about this rule is to conceive of Agr node insertion as applying at the maximal projection of DegP. The rule does not apply at every Deg or even at every DegP; it applies only in the context of an adjacent NP, accounting for the phrasal nature of the inflectional suffix. ${ }^{3}$ The rule in (9) will result in the following structure, with Agr surfacing between DegP and NP:

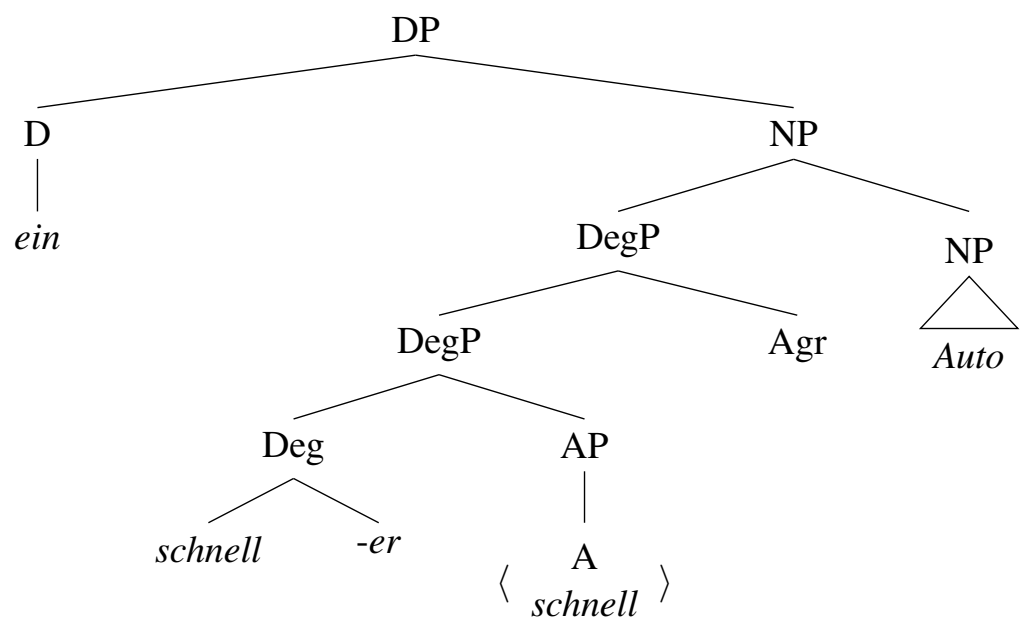

The system so far has explained where Agr is inserted, but not how it comes to expone inflectional morphology. To address this issue, I follow Norris $(2012,2014)$ by adopting his twostep system. In the syntax, features percolate to DP from heads throughout the nominal, with $\phi$-features contributed from (functional) projections below D and case assigned from the verbal layer to the entire DP. In the postsyntax, the percolated features on DP are copied onto the inserted Agr nodes according to the following rule (Norris 2014: 157):

a. Feature Copying (concord):

For every unvalued feature $\left[\mathrm{F}:[]\right.$ on an Agr node $\mathrm{Z}_{\mathrm{Agr}}$, copy the value from a projection XP iff:

b. XP has a value for $[\mathrm{F}:[]([\mathrm{F}: \alpha])$

c. XP includes $\mathrm{Z}_{A g r}$,

d. There is no YP such that YP has a value for [F:_], YP dominates $\mathrm{Z}_{A g r}$, and $\mathrm{XP}$ dominates YP (i.e. copy the closest value)

\footnotetext{
${ }^{3}$ This rule may also shed light on the fact that predicative adjectives lack inflection, though I lack the space to go into this issue here. The asymmetry in agreement would be a product of the postsyntax, rather than a syntactic fact.
} 
The Agr node inserted at DegP will get the features of DP copied onto it, as shown in (12):

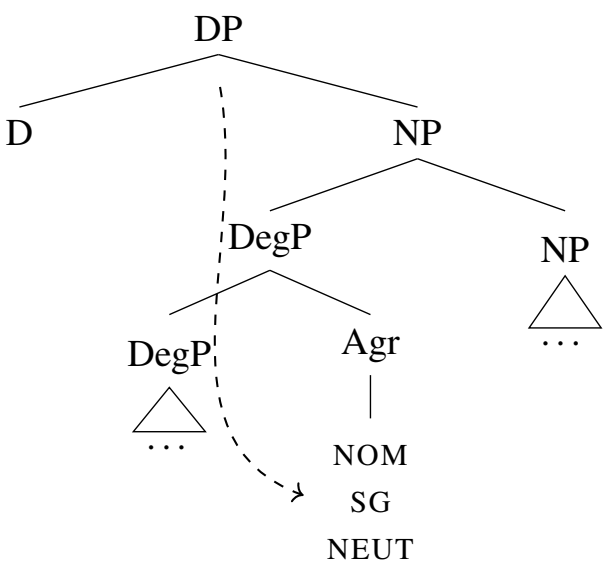

Making use of the framework of Distributed Morphology (Halle and Marantz 1993), I assume Agr node insertion, as a form of morphological concord, precedes other postsyntactic operations, consistent with the order of operations proposed by Arregi \& Nevins (2012):

Table 1: The order of postsyntactic operations (Arregi and Nevins 2012)

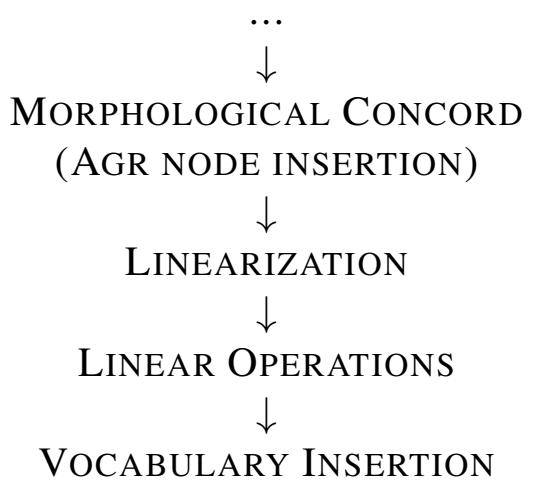

I propose further that the inflectional morpheme that comes to expone Agr ends up as a suffix on the right-most element as an instance of local dislocation (Embick and Noyer 2001). Local dislocation rebrackets adjacent material, for example converting (13a) to (13b):
a. $[\mathrm{X} *[\mathrm{Z} * \mathrm{Y}]]$
b. $[[\mathrm{X} * \mathrm{Z}] * \mathrm{Y}]$

Returning to the example of the synthetic comparative, the postsyntactic derivation then proceeds as in (14) below. I write the exponed version of the AGR node here for expository purposes (e.g. -es in the case of the nominative neuter singular feature bundle), though vocabulary insertion in fact occurs after linearization is complete, in accordance with the order of operations in Table 1.

a. Linearization:

$$
\left[{ }_{\operatorname{Deg} P}[\operatorname{Deg} P \text { schnell } * \text { er }] * \text { es }\right]
$$




\section{b. Local dislocation:}

$[\operatorname{Deg} P[\operatorname{Deg} P$ schnell $*$ er $*$ es $]]$

\section{c. Surface form:}

schnelleres

Following these steps, the account correctly predicts that inflection will occur outside the degree morpheme in synthetic comparatives if AGR is inserted at DegP (synthetic superlatives will work in much the same way). ${ }^{4}$ Returning to the problem of analytic equatives, the present proposal likewise extends to these cases, in which inflection does not occur on Deg. I repeat example (6) in (15a), and give the corresponding structure in (15b) after the rule for Agr-node insertion has inserted Agr at DegP:

a. ein so(*-es) schlecht-es Hotel

a so-INFL bad-INFL hotel 'as/so bad a hotel'

b.

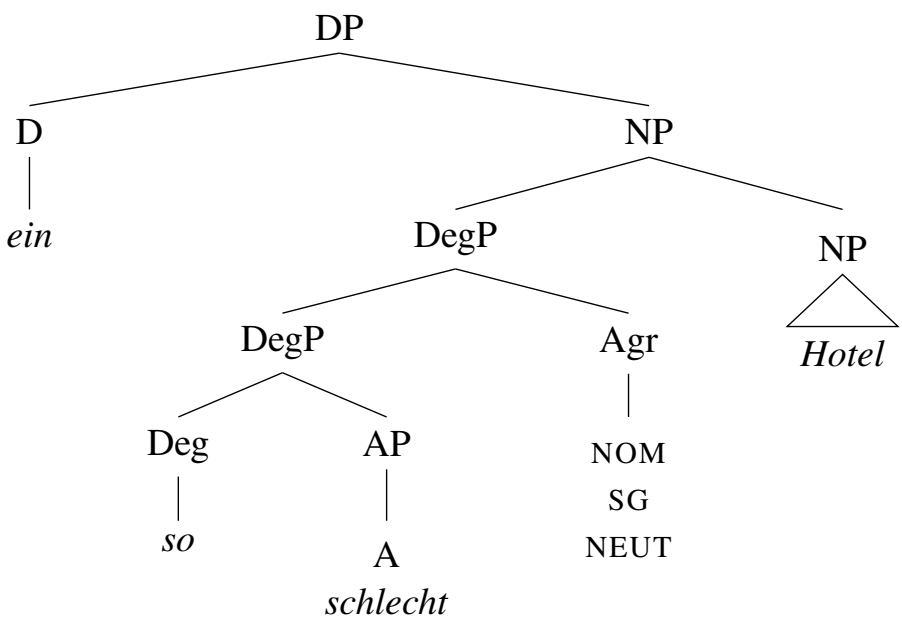

Because the Agr node is inserted at the edge of DegP, and the right-most element element inside DegP is the adjective schlecht ('bad'), the account correctly predicts that inflection will only occur on A and not Deg in pre-nominal analytic degree constructions:

a. Linearization:

$[\operatorname{Deg} P[\operatorname{Deg} P$ so schlecht $] *$ es $]$

b. Local dislocation:

$[\operatorname{Deg} P[\operatorname{Deg} P$ so schlecht $*$ es $]]$

c. Surface form:

so schlechtes

To summarize, by modifying Norris's proposal to the effect that Agr is inserted at DegP rather than $\mathrm{A}$, the inflection observed on pre-nominal degree modifiers is straightforwardly accounted for, both in the analytic and synthetic case. In the next section, I provide further motivation for the present account based on the inflection of complex degree modifiers.

\footnotetext{
${ }^{4}$ Note that inflection is only successful in the case that the right-most element in the DegP is an adjective (and not, e.g., a noun). I do not address this here, but see van Riemsdijk (1998) for related discussion.
} 
4. Complex degree modifiers. Another problem for Norris's (2014) account is found in phrasal inflection in complex de-gree modifiers that contain an overt standard of comparison (17) or equation (18).

a. ein [braun-er als braun-es] Auto

a brown-COMP than brown-INFL car

b. *ein [braun-er-es als braun(-es)] Auto

a brown-COMP-INFL than brown-INFL car

'a car that's browner than brown.'

(Roehrs 2006: 222)

a. das [so schnell wie möglich-e] Aufräumen

the as fast as possible-INFL cleaning-up

b. *das [so schnell-e wie möglich(-e)] Aufräumen

the as fast-INFL as possible-INFL cleaning-up

'the cleaning up that's as fast as possible'

(Roehrs 2006: 222)

As can be expected from a system of phrasal inflection, only the rightmost adjective in both (17) and (18) may be inflected. In neither case is the inflected adjective the head of the modifier - it is simply the rightmost element. Such examples therefore clearly reveal that the agreement morpheme tacks on to whatever the rightmost adjective is, regardless of head status or the presence of other adjectives, warranting some refinement to Norris's (2014) proposal.

On the current approach, the inflectional pattern follows however from the fact that Agr is inserted just once, at DegP. The underlying structure of a pre-nominal comparative such as that in (17) is shown in (19):

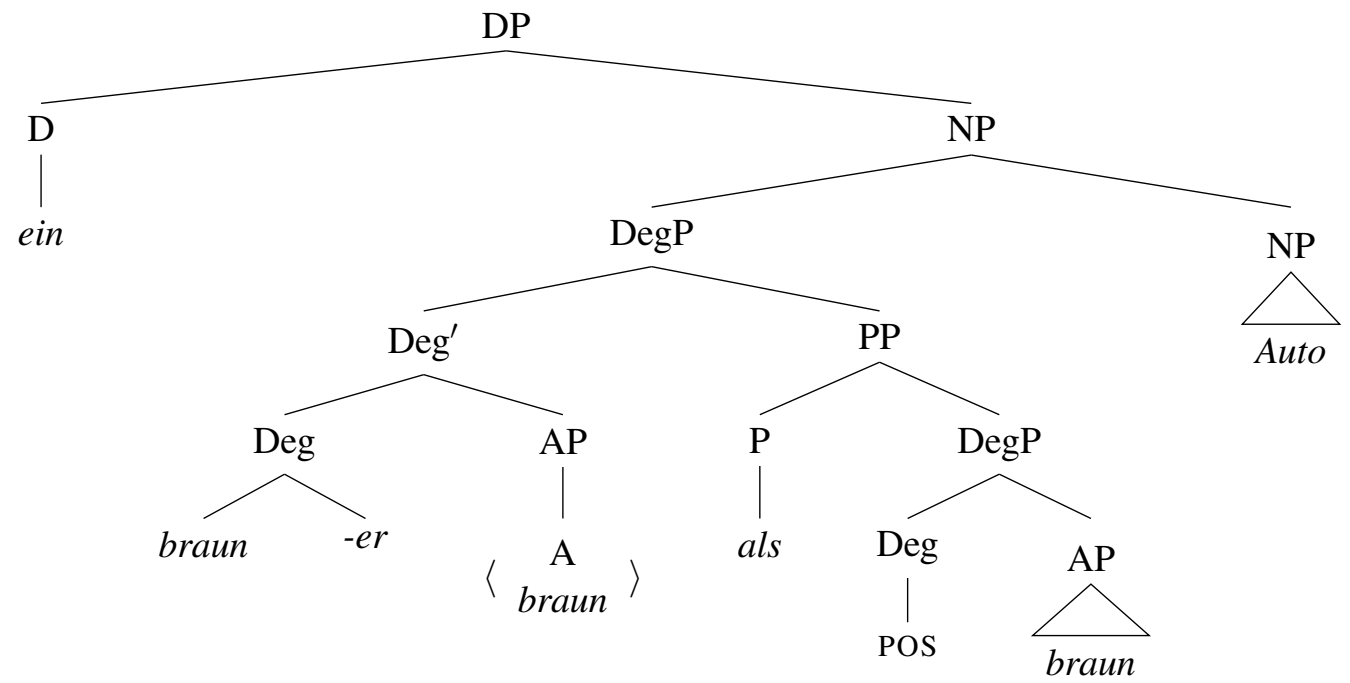

Given this stucture, the rule of Agr-node insertion given in (9) will apply at the DegP adjacent to the noun, in this case Auto ('car'). This rule is repeated below in (20):

Agr node insertion (for adjectival concord): $\mathrm{DegP} \rightarrow\left[\mathrm{DegP}_{\mathrm{Agr}}{ }^{0}\right]_{\operatorname{Deg} P} / \ldots \mathrm{NP}$ 
This will yield the following structure:

DP

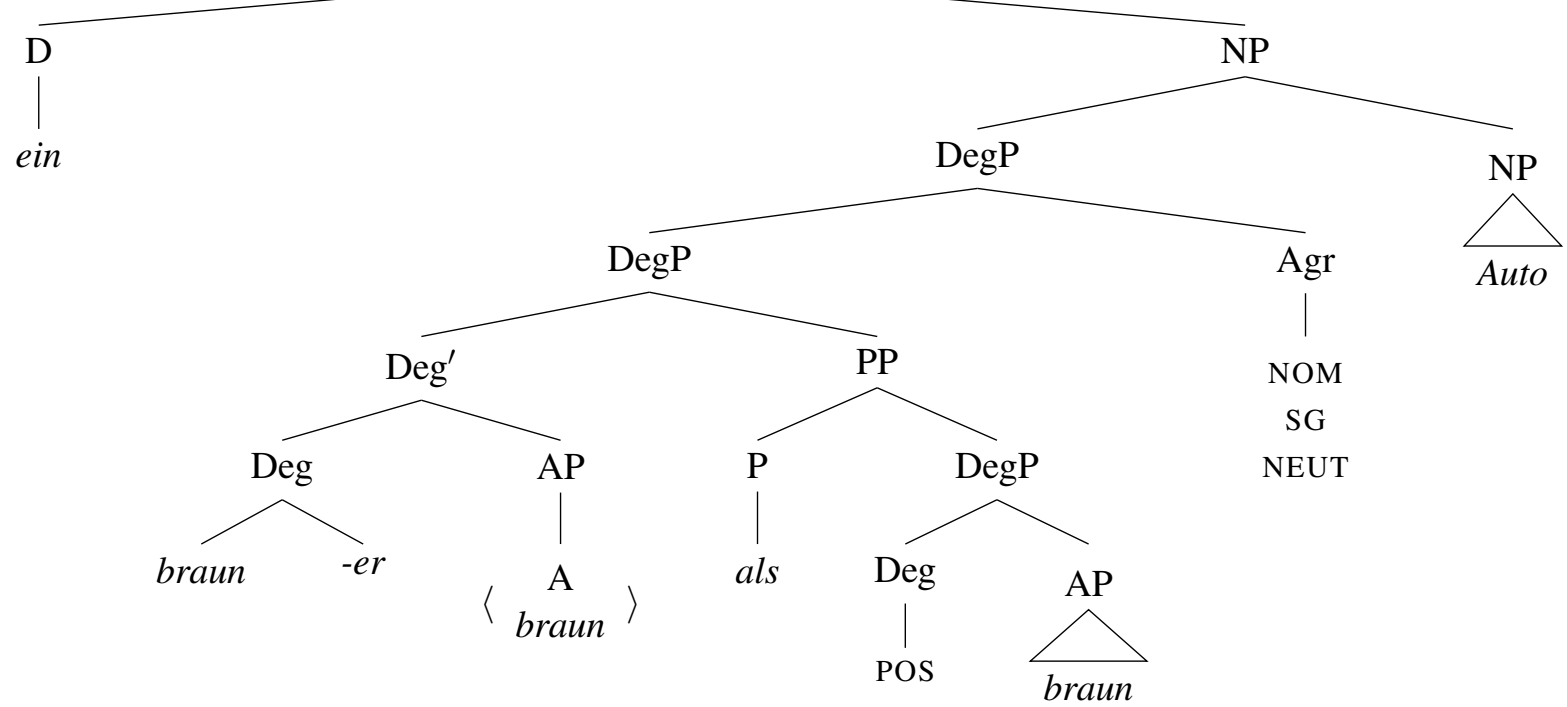

The structure in (21) is then linearized, and Agr undergoes Local Dislocation with the rightmost element, which in both cases is the adjective housed in the standard of comparison/equation, rather than the head of the entire modifier:

a. Linearization:

$[\operatorname{Deg} P[\operatorname{Deg} P$ braun $*$ er $*$ als $*$ braun $] *$ es $]$

b. Local dislocation:

$[\operatorname{Deg} P[\operatorname{DegP}$ braun $*$ er $*$ als $*$ braun $*$ es $]]$

c. Surface form:

brauner als braunes

The upshot of this is that the phrasal inflection of both synthetic and analytic degree expressions in both simplex and complex modifiers is explained if Agr is inserted at DegP, not A or Deg.

\section{Coordination}

5.1. ATB INFLECTION. The phrasal nature of inflection faces a potential counterexample from coordination. When two (or more) adjectives are coordinated, all adjectives must be inflected (23a). The proposal so far, however, falsely predicts (23b) to be grammatical:
a. ein [alt-es und wichtig-es] Buch an old-INFL and important-INFL book 'an old and important book'
b. *ein [alt und wichtig-es] Buch an old and important-INFL book Intended: 'an old and important book' 
This is because Agr will be inserted at DegP, resulting in the structure in (24):

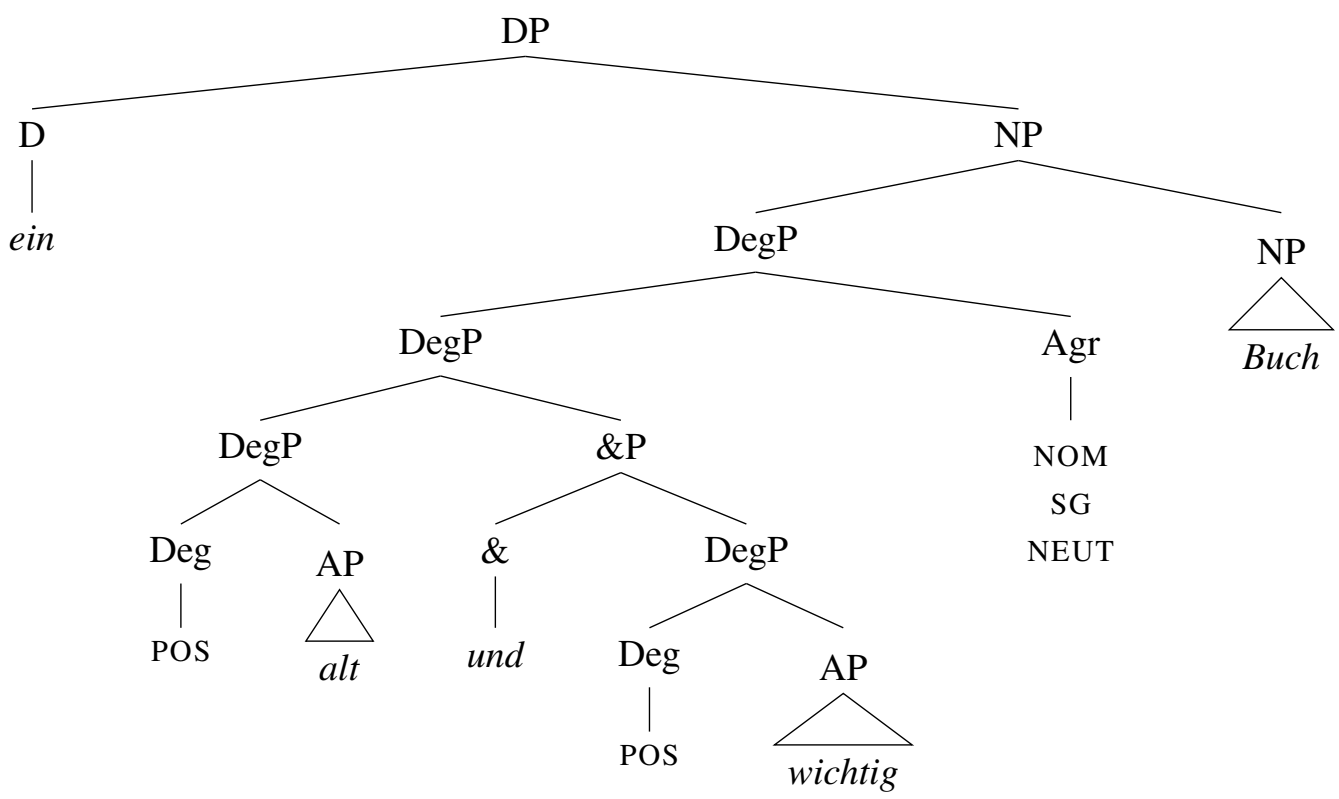

To account for this apparent counterexample to the present proposal, I follow McNabb's (2012) work on definiteness marking in degree modification in Arabic and Hebrew. ${ }^{5} \mathrm{McNabb}$ proposes that Agr may attach pointwise in coordinated structures (see also Hankamer 2008; Kramer 2010), which I argue can also explain the ATB inflection of coordinated adjectives in German. The idea behind this proposal is that coordinate structures consist of unordered sets, as in (25). Linearized order mirrors their hierarchical structure, but they are still visible to postsyntactic operations as individual structures that may be acted upon by, e.g., local dislocation.

(25) Coordination Structure Linearization: $[\mathrm{X}] \&[\mathrm{Y}] \rightarrow\{\mathrm{X}, \mathrm{Y}\}$

Both conjuncts in the ordered set are therefore subject to local dislocation with Agr postsyntactically, as long as the coordinated phrase is the right-most modifier preceding the noun.

Agr Pointwise Attachment: $\{\mathrm{X}, \mathrm{Y}\} *$ AGR $\rightarrow\{\mathrm{X}-\mathrm{AGR}, \mathrm{Y}-\mathrm{AGR}\}$

Adopting this proposal makes the correct prediction that both conjuncts will become inflected:

a. Linearization $\left[\operatorname{Deg} P\left[\operatorname{Deg} P\{\text { alt, wichtig }\}_{\text {und }}\right] *\right.$ es $]$

b. Local dislocation $\left[\operatorname{DegP}\left[\operatorname{Deg} P\{\text { alt, wichtig }\}_{\text {und }} *\right.\right.$ es $\left.]\right]$

c. Pointwise attachment of Agr $\left[\operatorname{Deg} P\left[\operatorname{Deg} P\{\text { alt-es, wichtig-es }\}_{\text {und }}\right]\right]$

d. Surface form altes und wichtiges

\footnotetext{
${ }^{5}$ While McNabb (2012) assumes a ternary structure, I adopt Munn's (1993) adjunction approach to coordination.
} 
5.2. AN ASIDE. The problem of coordinated adjectives is unaccounted for by existing syntactic accounts of inflection as well (i.a. Corver 1997; Leu 2008; Roehrs 2006, 2013; cf. Schoorlemmer 2009, 2012). One representative example of a syntactic account comes from Roehrs (2015), who proposes a head in the extended projection of DP that takes A as its complement (licensed by the presence of the Agr node in the DP spine).

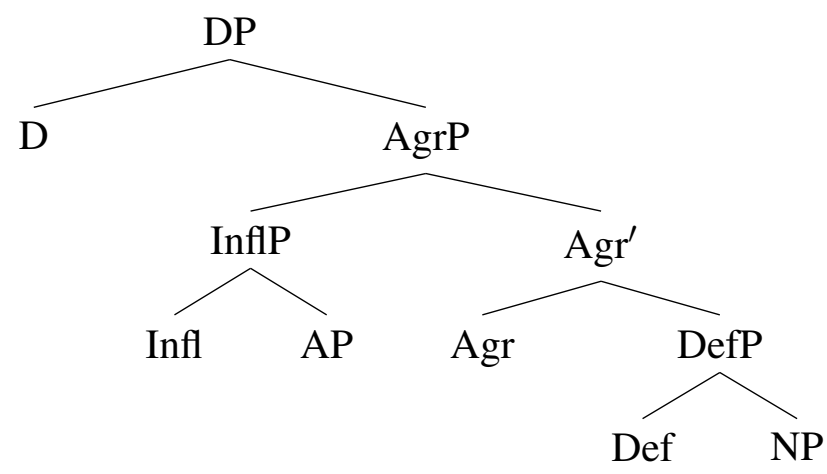

Roehrs (2015: 246)

Such accounts handle phrasal inflection well, but likewise need something like pointwise attachment in the postsyntax to explain ATB inflection in coordination, as the structure in (28) erroneously predicts phrasal inflection in coordination without it.

5.3. SAME inflection, DifFERENT inter PRETATION. Returning to the current proposal, one piece of evidence lending support to the need for pointwise attachment comes from ambiguous scope associated with degree modifiers such as sehr ('very'). On both its narrow and wide scope interpretations, both adjectives in a coordinate structure must be inflected. On the narrow scope reading, this falls out from the current analysis due to the fact that the coordinate structure is adjacent to the insertion site of the Agr node, and so Agr must undergo pointwise attachment:

narrow scope

a. ein [[sehr lang-es] und [langweilig-es]] Buch a very long-INFL and boring-INFL book 'a book that's boring and very long'

b.

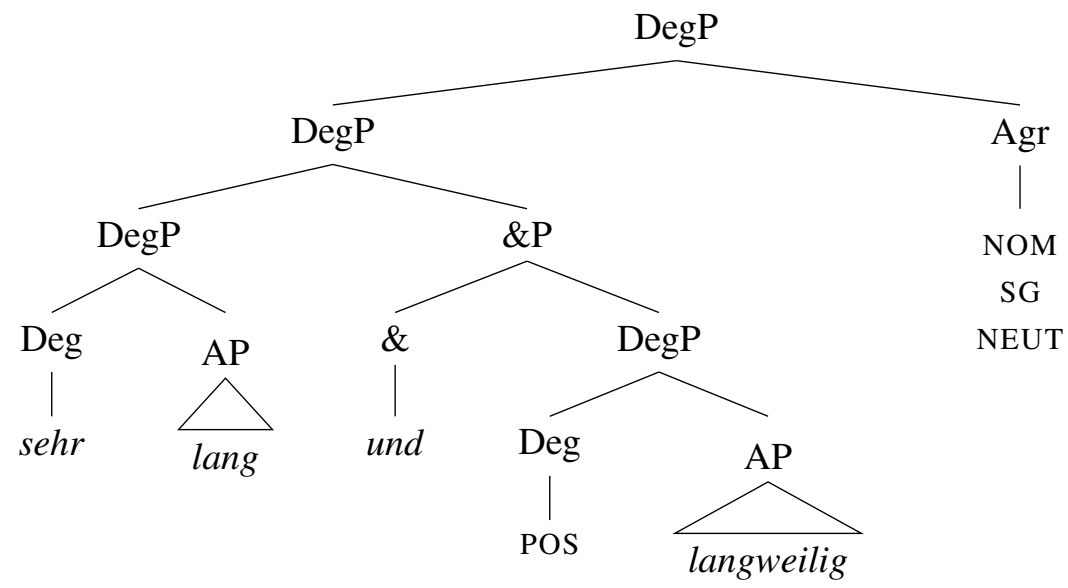


These facts are also consistent with an alternative proposal however, namely that Agr is inserted not at the maximal DegP, but at each DegP. The wide scope reading shows that this analysis is not tenable, as we would expect to see phrasal inflection only if this were the case.

\section{wide scope}

a. ein [sehr [lang-es und langweilig-es]] Buch a very long-INFL and boring-INFL book 'a book that's very long and very boring'

b.

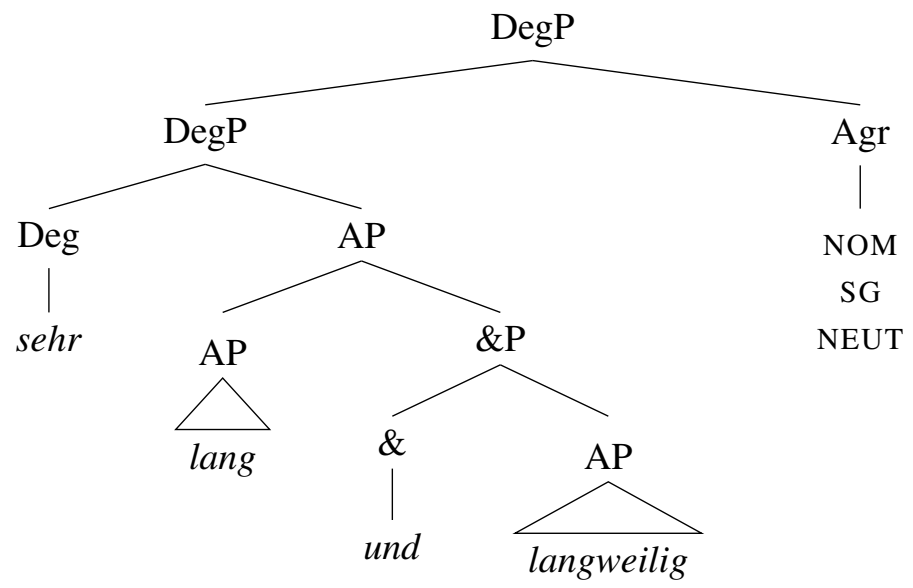

Without pointwise attachment, we would expect to find the ungrammatical (31) on the wide scope reading, as only one DegP is present to host the Agr morpheme, at the right edge of DegP only:

*ein [sehr [lang und langweilig-es]] Buch

a very long and boring-INFL book

Intended: 'a book that's very long and very boring'

The scope facts therefore lend evidence to the need for pointwise attachment, as opposed to an alternative proposal, according to which Agr in inserted at each DegP.

5.4. DifFERENT INFLECTION, DifFERENT INTERPRETATION. Another type of evidence lending support to the need for pointwise attachment of Agr comes from phrasal inflection in prenominal constructions involving participles. For example, the present participle scheinend 'seeming' may occur with other adjectives pre-nominally: ${ }^{6}$

$$
\text { eine [ausweglos scheinen-d-e] Lage }
$$

a hopeless seeming-ADJ-INFL situation 'a hopeless-seeming situation'

The present participle in attributive position is formed by adding the suffix $-d$ to the infinitive. $^{7}$ I assume a structure along the following lines:

\footnotetext{
${ }^{6}$ Schlögel, Karl: Petersburg, Munich \& Vienna: Carl Hanser Verlag 2002, pg. 515. Accessed via the Digitales Wörterbuch der deutschen Sprache (Digital Dictionary of the German Language), accessible at https: //www.dwds.de/.

${ }^{7}$ As Ed Rubin (p.c.) points out, another way to think about the formation of the present participle is to assume that the adjectivalizer is in fact -end, which suffixes onto the verb stem. Either approach is consistent with the point I make here.
} 


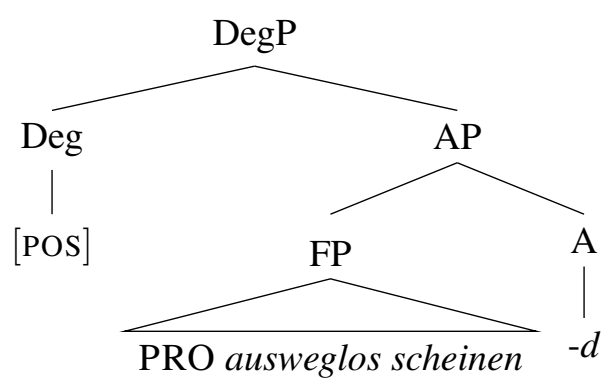

In a case such as (33), Agr will be inserted at DegP and the predicted result is correct, in which only the right-most adjective scheined bears inflection:
a. Linearization:
$[\operatorname{Deg} P[\operatorname{Deg} P$ ausweglos scheinend $] * \mathrm{e}]$
b. Local dislocation:
$[\operatorname{Deg} P[\operatorname{Deg} P$ ausweglos scheinend $* \mathrm{e}]]$
c. Surface form:
ausweglos scheinende

However, we also see mixed cases in coordination and variation in inflection. In the first case (35), only the participle is inflected: both preceding adjectives are embedded under seem.
eine $[[$ kompetent und geeignet $]$ scheinen-d-e $] \quad$ Politikerin
a competent and suitable seeming-ADJ-INFL politican
'a politician that seems competent and suitable'

The modifier in example (35) exhibits the expected phrasal inflection. Both adjectives are embedded under seem in the FP in (36), which is likewise reflected in the resulting meaning of a politician that is both competent-seeming and suitable-seeming:

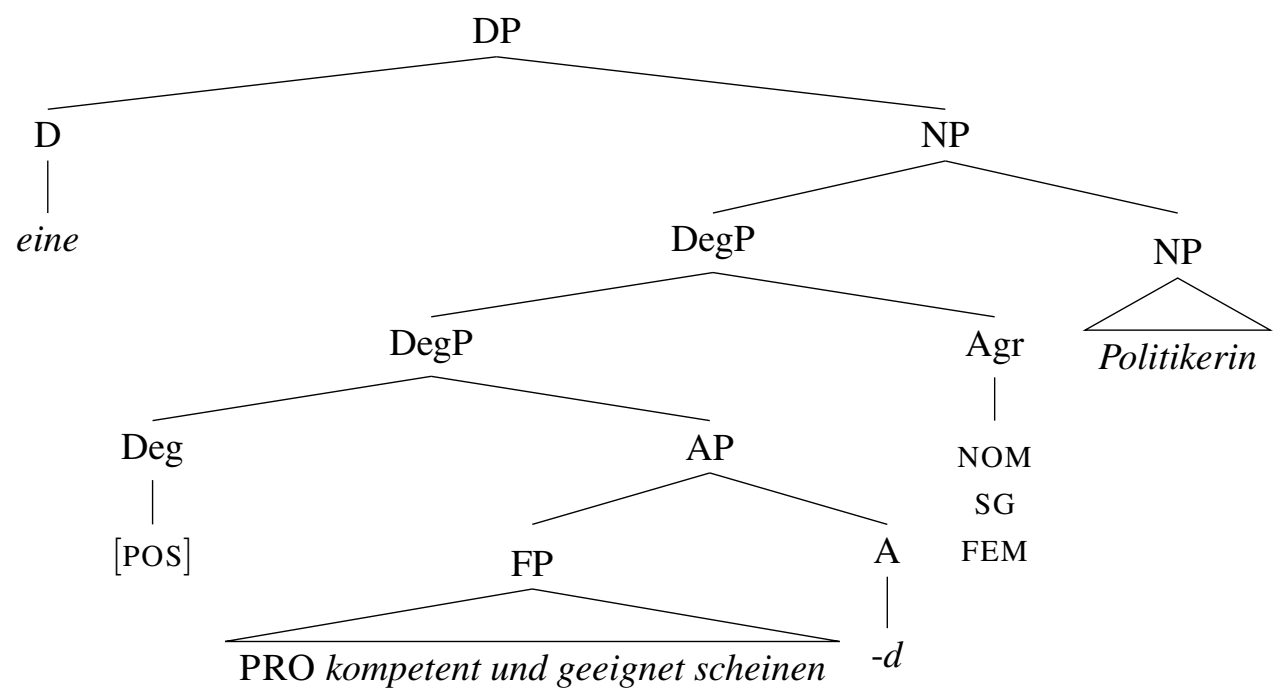


Given this structure, the present proposal makes the correct predication that neither kompetent nor geeignet should be inflected: the coordinated AP is embedded inside FP and is therefore not adjacent to Agr. For this reason, pointwise attachment does not apply: local dislocation is crucially local, and both conjuncts are too far away. This is shown in the steps in (37), as well.

\section{a. Linearization:}

$[\operatorname{Deg} P[\operatorname{Deg} P$ kompetent $*$ und $*$ geeignet $*$ scheinen $* \mathrm{~d}] * \mathrm{e}]$

b. Local dislocation:

$[\operatorname{Deg} P[\operatorname{Deg} P$ kompetent $*$ und $*$ geeignet $*$ scheinen $* \mathrm{~d} * \mathrm{e}]]$

\section{c. Surface form:}

kompetent und geeignet scheinende

In the second case however, the left-most adjective is also inflected, while it is only the rightmost adjective that is embedded under seem.

$$
\begin{aligned}
& \text { eine }[[\text { kompetent-e }] \text { und [geeignet scheinen-d-e }]] \text { Politikerin } \\
& \text { a competent-INFL and suitable seeming-ADJ-INFL politican } \\
& \text { 'a politician that is competent and seems suitable' }
\end{aligned}
$$

The difference in interpretation - one of a politician that is competent and suitable-seeming accordingly reflects a different underlying structure, as shown in (39). In this case, unlike in (36), the coordinated phrase is directly adjacent to the inserted AGR node.

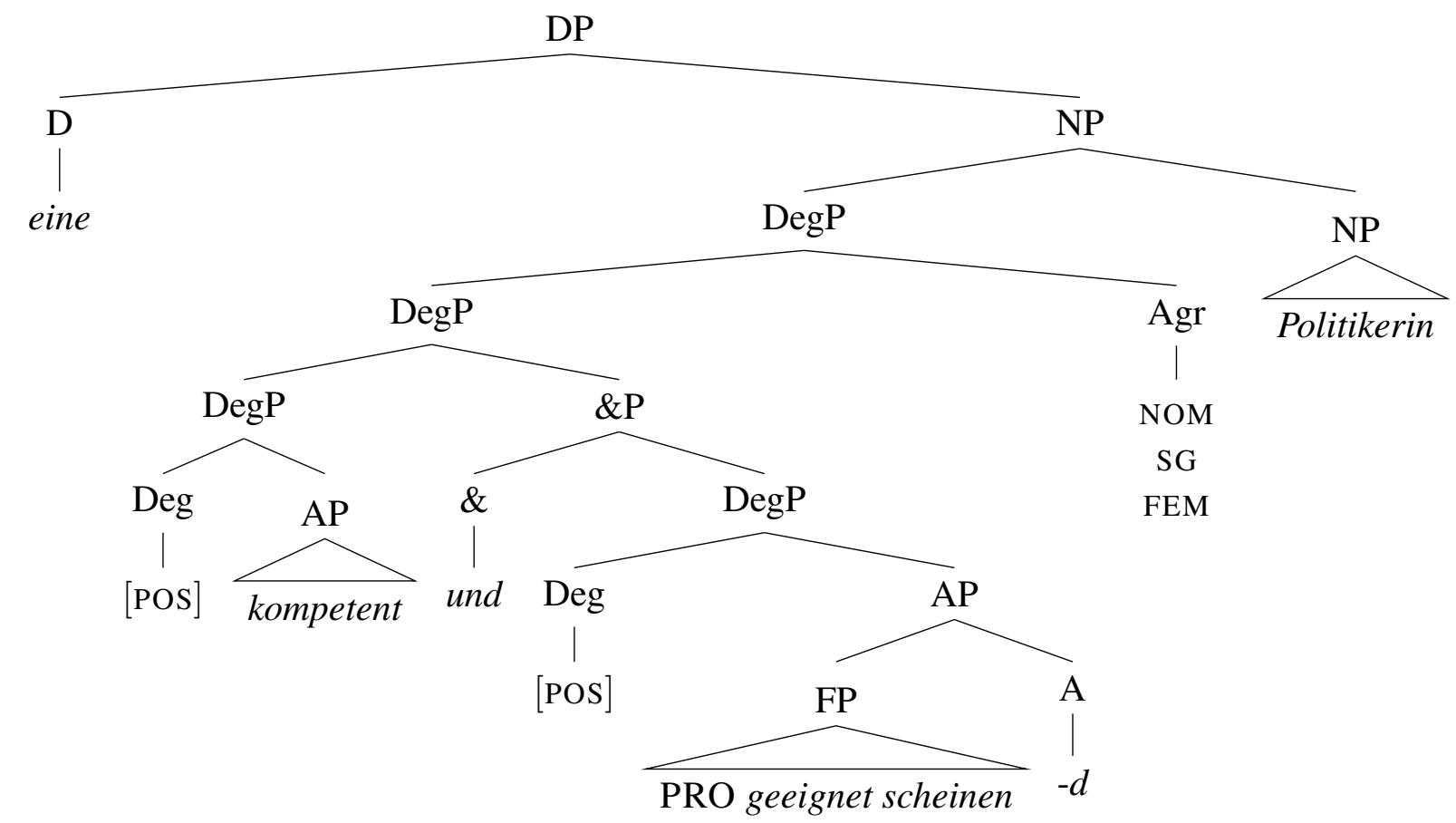

In (39), coordination is directly adjacent to NP, rather than embedded inside the FP. The present account therefore correctly predicts the inflectional pattern once again: since the locality condition is met, pointwise attachment obligatorily applies, and ATB inflection results. The postyntactic steps after AGR-node insertion are given in (40): 
a. Linearization

$\left[\operatorname{DegP}\left[\operatorname{DegP}\{\text { kompetent, geeignet scheinend }\}_{\text {und }}\right] * \mathrm{e}\right]$

b. Local dislocation

$\left[\operatorname{Deg} P\left[\operatorname{Deg} P\{\text { kompetent, geeignet scheinend }\}_{\text {und }} * \mathrm{e}\right]\right]$

c. Pointwise attachment of Agr

$\left[\operatorname{DegP}\left[\operatorname{DegP}\{\text { kompetent-e, geeignet scheinend-e }\}_{\text {und }}\right]\right]$

d. Phonological representation

kompetente und geeignet scheinende

In sum, we find evidence for the need for pointwise attachment both from inflectional facts concerning scope and participal constructions in German. In the case of the former, we find one inflectional pattern with two distinct underlying structures. In the case of the latter, we find two inflectional patterns reflecting this difference in structure. An account in which AGR is inserted at DegP and undergoes local dislocation just in case it is adjacent to a coordinated phrase makes precisely the right predictions in both cases.

6. Conclusion. As currently formulated, postsyntactic approaches to adjectival concord are untenable for German. We see this in synthetic comparatives and superlatives, complex degree modifiers, and constructions involving pre-nominal inflected participles such as seeming. I have argued that we can capture all of these facts with the proposal that are inserted at maximal DegPs, conditioned by the presence of an adjacent NP. I have shown moreover that pointwise attachment of Agr ex-plains a potential counterexample of ATB inflection presented by coordinated adjectives.

\section{References}

Abney, Steven. 1987. The English Non Phrase in its Sentential Aspect. Doctoral Dissertation, MIT.

Alrenga, Peter, Christopher Kennedy, and Jason Merchant. 2012. A New Standard of Comparison. In Proceedings of WCCFL 30, ed. Nathan Arnett and Ryan Bennett, 32-42. Cascadilla Proceedings Project.

Arregi, Karlos, and Andrew Nevins. 2012. Morphotactics: Basque Auxiliaries and the Structure of Spellout. Dordrecht: Springer.

Baier, Nico. 2015. Adjective Agreement in Noon: Evidence for a Split Theory of Noun-Modifier Concord. In Proceedings of nels 45, 67-80. GLSA.

Bobaljik, Jonathan. 2008. Where's phi? In Phi theory: Phi features across interfaces and modules, 295-328. Oxford University Press.

Bobaljik, Jonathan. 2012. Universals in comparative morphology: Suppletion, superlatives, and the structure of words. MIT Press.

Corver, Norbert. 1990. The syntax of Left Branch Constructions. Doctoral Dissertation, Tilburg University.

Corver, Norbert. 1997. The internal syntax of the Dutch extended adjectival projection. Natural Language and Linguistic Theory 15.2:289-368.

Deal, Amy Rose. 2016. Plural exponence in the Nez Perce DP: a DM analysis. Morphology 26.3-4:313-339. 
Embick, David, and Rolf Noyer. 2001. Movement operations after syntax. Linguistic Inquiry 32.4:555-595.

Grimshaw, Jane B. 1991. Words and Structure. Unpublished manuscript, Brandeis University.

Grosu, Alexander. 2003. 'Transparent' free relatives as a special instance of 'standard' free relatives. In From NP to DP. Volume 1: The syntax and semantics of noun phrases, ed. Martine Coene and Yves D'hulst, 139-178. Amsterdam: John Benjamins.

Halle, Morris, and Alec Marantz. 1993. Distributed Morphology and the pieces of inflection. The view from building $20111-176$.

Hankamer, Jorge. 2008. Ad-phrasal affixes and suspended affixation. Paper presented at the LSA annual meeting, Chicago, IL.

Kiparsky, Paul. 2005. Blocking and periphrasis in inflectional paradigms. In Yearbook of Morphology, ed. J. van Marle and G. Booij, 113-135. Springer Dordrecht.

Kramer, Ruth. 2010. The Amharic Definite Marker and the Syntax-Morphology Interface. Syntax 13:196-240.

Leu, Thomas. 2008. The internal syntax of determiners. Doctoral Dissertation, NYU.

McNabb, Yaron. 2012. The syntax and semantics of degree modification. Doctoral Dissertation, University of Chicago, Chicago, IL.

Munn, Alan. 1993. Topics on the syntax and semantics of coordination. Doctoral Dissertation, University of Maryland.

Norris, Mark. 2012. Towards an analysis of concord (in Icelandic). In Proceedings of the west coast conference on formal linguistics (wccfl) 29, 205-2013. Cascadilla Proceedings.

Norris, Mark. 2014. A Theory of Nominal Concord. Doctoral Dissertation, UC Santa Cruz.

Noyer, Rolf. 1997. Features, Positions and Affixes in Autonomous Morphological Structure. Garland Publishing.

Pietraszko, Asia. 2017. Obligatory CP nominalization in Ndebele. Unpublished manuscript, University of Connecticut. Published on Lingbuzz: http://lingbuzz.auf.net/lingbuzz/003273.

van Riemsdijk, Henk. 1998. Head movement and adjacency. Natural Language and Linguistic Theory 16.3:633-679.

Roehrs, Dorian. 2006. The Morpho-Syntax of the Germanic Noun Phrase: Determiners Move into the Determiner Phrase. Doctoral Dissertation, Indiana University.

Roehrs, Dorian. 2013. The inner makeup of definite determiners: The case of Germanic. Journal of Germanic Linguistics 25(4):295-411.

Roehrs, Dorian. 2015. Inflections on pre-nominal adjectives in Germanic: Main types, subtypes, and subset relations. Journal of Comparative Germanic Linguistics 18:213-271.

Schoorlemmer, Erik. 2009. Agreement, dominance and doubling: The morphosyntax of DP. Doctoral Dissertation, LOT, The Netherlands.

Schoorlemmer, Erik. 2012. Definiteness marking in germanic: Morphological variations on the same syntactic theme. The Journal of Comparative Germanic Linguistics 45(2):107-156.

Sigurðsson, Halldór Ármann. 2015. Gender: a PF reflection of an edge linker. Unpublished manuscript, Lund University. Published on LingBuzz: http://ling.auf.net/lingbuzz/002467. 